\title{
Rethinking on Artistic Design Education Development under the Visual Threshold of Creative Industry
}

\author{
Jing Wen ${ }^{1}$, Yingjie $\mathrm{Lu}^{1}$ \\ ${ }^{1}$ College of the Arts, Nanchang Institute of Technology, Nanchang, 330044, China
}

Keywords: Creative industry; Artistic design; Education

\begin{abstract}
In 1990s, the economic function of our creative industry was gradually approved, and the creative industry of all western countries was also booming in their own directions; the global art industry presented a picture of great prosperity. In the creative industry, the individual contribution is extremely important and the talent education is also decisive. Therefore, good artistic design education actually is the first step to propel the development of industry and is also an imminent task for colleges and universities nowadays.
\end{abstract}

\section{Current situation of the creative industry}

\section{Current situation of the world}

In the current background of the times, the cultural creative industry has become the raising-star industry of the world. But several years ago, the creative industry was just an emerging industry in the newspapers. The difference in only a single world shows that people gradually approve such industry. As obviously indicated in the Creative Economy Report 2010, the creative economy has become the most vigorous economic part in the world economy; the expansion of employment income and import and export trade potential created by the industry is also the best in short time. At the same time, the irreplaceability for increasing the cultural diversity makes it become the future development direction of developing countries.

\section{Current situation of our country}

In the statistics of 2012, Beijing Municipal Bureau of Statistics concluded that the output value of cultural creative industry of the whole Beijing reached $12.6 \%$ of Beijing's GDP; Shanghai's output value reached 5.6\% and Hangzhou's output value reached $11.9 \%$ respectively. The cultural creative industry got the first name in the tertiary industry, so its strength to push the local development cannot be underestimated. However, only the first phase of our creative industry was just completed right now. From an objective point of view, compared with foreign countries, our creative industry is still in the primary stage for the two reasons below: firstly, it seems that the cultural creative industry is flourishing but, for the development areas, it is still limited in the central cities our the national key economic areas, namely, the first-tier cities. Actually this is not our future development direction. Since we are a developing country, it is our only way which must be passed to develop the second-tier and third-tier cities and it is the mark of shaping this industry to form the regional collective industry network. Secondly, after all, the creative products are not the rigid demand commodities and there is still a big gap between our society's sales of spiritual consumption and that of the developed western countries, so we have large space for improvement in this aspect.

\section{Existing problems}

According to the international development trend of creative industry, the creative industry mentioned by us is not just one part of the cultural industry system. On the basis of the statistical data in the Cox Review of UK, the creative industry has stepped into the systematic innovation stage, exceeding the level of the traditional cultural industry; the "design" realizes the process from creation to invention. Cox also particularly points out that the innovation industry shall be the foundation to reintegrate the UK's manufacturing industry. At the same time, the western countries have expanded this from the creative industry to the whole industry. Such popularization level will certainly be rather helpful to develop the industry. But the popularization level of creative industry in our country is still pretty low. 


\section{Domestic artistic design education}

\section{Current situation of design education}

Energetic supports by policies

As clearly pointed out in the " $12^{\text {th }}$ Five-Year Plan" of our country, both the country and society hope to promote the development of cultural creative industry to make it become the "pillar industry in the national economy". With the unceasing development of technology and society, it is an irresistible trend to develop "Created in China" because the development pattern of the manufacturing and processing industry with both ends of the production process on the world market cannot be a long-term policy. Since only after we thoroughly change the international impression of "Made in China" into "Designed in China", we can unashamedly say that we have the cultural competitiveness with that of Europe and America shoulder to shoulder. As the history of Chinese culture is more than five thousand years, both its inside information and connotation cannot be surpassed by any other culture; so we have a rather solid foundation for the existing cultural creative industry. But the most basic and important element in the creative industry is the creative talent. With the society's increasing need for creative talents, the scale of higher artistic design education is extending continuously. The following can be estimated from the data acquired through some platforms: at present, there are thousands of colleges and universities which have the design major or analogical design major; there are hundreds of thousands of students newly enrolled yearly, including the non-art major students enrolled according to the method for enrollment of art students approved by the Ministry of Education and they major in the analogical art (for example, Game Technologies) in colleges and universities; some students with high scores recruited through the common entrance examination also major in designs (for example, Landscape Architecture). Therefore, the design majors have become the most popular and fastest growing majors nationwide.

Huge realistic gap

With the expansion of enrollment scale, we still need to pay attention to some problems. In reference to the art education, almost all the scholars in relevant majors in the educational circle have the consensus that "China's artistic design education falls far behind the practice of modern manufacturing industry”, as quoted from Matthias, a Germany scholar. We have to say it is pertinent to evaluate both the quantity and quality of the students in this major like this. In quantitative terms, our eyes cannot be only limited to the first-tier cities such as Beijing and Shanghai. Thought it is impractical to compare with the Europe and America, we can make a comparison with India. In the terms of employment, Bollywood is such a good example that there are a billion people in the one industrial cluster of Bollywood, including the directors, producers, actors and other film and television industries; there are even more than 5,000,000 persons if the surrounding industries are included. However, the similar industrial clusters in our country are just in the start-up stage; the quantity of employees in this industry including the management personnel in the creative industry companies only accounts for less than one thousands of the quantity of social employees. It is interesting that $80 \%$ employees in the industry are under the age of 25 and less than $30 \%$ have more two years of working experience. According to the experience of the employers concerned, a university graduate can become a designer, able to work independently, only after the growth for eight or ten years. that is to say, eighty percent employees in the industry are exactly the graduates in the "most popular" majors, as mentioned by us, only accounting for less than eighty percent of one thousandth employees nationwide. Besides, we also need to introduce in a lot of professionals abroad every year. Thus, it can be seen that the existing higher education fails to satisfy the market's need for graduates. A large number of students need to face the ability deficiency, which is a doubt for the professional education of creative design in the market economy. A scholar said that the late starting and heavy task in domestic design education are not the reasons for the generation's shifting of responsibility. Also take the films and televisions for example. China's animations, Three Monks, Uproar in Heaven and Prince Nezha's Triumph against Dragon King and America's Snow White of the same period were almost in the same starting line in the 1960s and 1970s. But nowadays America have monopolized $92.3 \%$ in the animated film industry while the quantity of employees concerned in 
China is less than half of those in South Korea. All the above data are sufficient to demonstrate the severe gap between the artistic design education in colleges and universities and the industry development in China.

\section{Problems to be resolved urgently}

At present, the most important problem is the severe discrepancy between design education and market, which cannot be simply generalized in accordance with the standard for higher artistic design neglecting educational practice, because speaking in general terms cannot solve the problem. Firstly, some teachers begin their teaching in colleges and universities directly after graduation, without sufficient practical experience. Particularly in recent years, with the colleges and universities' increasingly high requirement for education background of teachers and increasingly heavy scientific research tasks, while finishing the teaching work, most teachers also need to complete the stipulated scientific research tasks synchronously. Besides, to promote their job titles, they often spend plenty of time in writing papers, so they have poor practical abilities, are alienated with the development trend of design and are unfamiliar with the market dynamics. Besides, our country lacks researchers in creation theories and there are only a very few of researchers in development strategies, which makes our "research talents", which are supposed to carry out researches, to teach students in the condition of insufficient practical experience; but the place where research talents are needed actually is still short of talents. Such phenomenon of putting the incidental before the fundamental largely affects the training of students and, later, the influenced students also become teachers, forming a vicious circle. Meanwhile, this also restricts the research and development of the creative industry system in our country. But in the western countries (as well as India mentioned above), their teachers are basically from the market. We can say that they "come to the platform with their experience”. At last, there are problems in teaching setting; the curriculum configuration is also not scientific. The traditional teaching management mode separates practice and teaching with unrelated courses filling in all the teaching links, so the students are not able to cope with the systematic professional work through fragmented knowledge, which is exactly the "poor quality of employees" said by the employers. Such education system leaves only a very few opportunities for teachers and students to enter into the market even to participate in job practice. That is how the discrepancy is widened.

Some colleges and universities go to other extreme, "dividing the content of a course into fragments and only offering the skills which seem to have direct effects." Although such skill-first thought seems to meet the employers' appetite, the graduates trained in this way can only have professional skills without corresponding basic artistic knowledge. They neither know the artistic design procedures of each industry at all nor have the consciousness of innovation and good cultural and artistic accomplishment, so they cannot arrive at the core positions of creative industry. Consequently, we have to bring in foreign professionals again. The artistic design education is only carried out in the design specialty because the domestic colleges and universities fail to connect the students in the cultural creative industry with the students majoring in non-artistic design. The most typical example is the majors related to auto design and manufacturing. The innovation ability in this aspect is really limited in our country, which is not just the responsibility of industrial design specialty but the lack of innovation ability in the whole industry; in the final analysis, it is because the employees only acquire professional skills, especially some engineering employees and a vast majority of employees including the management layer lack the artistic design thinking. With the time going by for tens of years, the design education has been largely improved in our country, but our domestic design education still cannot satisfy the dynamic market and such gap shows a tendency of continuous enlargement.

\section{International artistic design education thinking and reference}

Now that the preceding part of this paper made some analyses and statements on the domestic artistic design education, the writer will make a further statement below according to the aforesaid two directions and by referring to the current situation of foreign design education: 


\section{Faculty}

The first problem is faculty. Due to the lack of experience, some teachers are not familiar with the industry chain; the teachers also lack competition under this system, so the colleges and universities restrained such reform and development. Many college and university teachers have such weakness. However, in the western design institutes, the method of employing most part-time teachers and a small part of full-time teachers is adopted (the small part of full-time teachers are the "research talents” mentioned in the preceding paragraphs”); they will hire some front-line design experts to give lessons with the purpose of bringing new concepts, new technological processes, new industrial standards, new industrial dynamics and new professional skills to the class to widen the students' thinking and horizon. For this reason, it is completely acceptable to employ some excellent design management personnel or designers to give lessons in universities in a short term because they are able to bring the cutting-edge design philosophy and experience to the students so as to enrich their horizon. More importantly, this also creates more changes for advanced studies and trainings to the in-service teachers. The university teachers should charge themselves in good time and participate in as many practices as possible after teaching so as to accumulate experience to enrich their teaching.

\section{Curriculum design}

To enhance the training of creative design talents, we need to analyze the development features of creative industry. Creative design and research, creative production, creative management, creative marketing and high-end inter-disciplinary talents are needed in a series of industrial and commercial operation systems constructed based on the planning, production, broadcasting and consumption of creative products. For this reason, the colleges and universities shall rely on advantageous educational resource to cooperatively build the production-learning-research platforms with enterprises so as to enhance the creative design talents' practical ability and creativity by using the enterprises' brand effect and professional talents and by relying on practices. In this way, it is more difficult for the colleges and universities to set their curriculums for artistic design specialty. Only when the colleges and universities systematically integrate the curriculums, the teaching will not lag behind the social needs. What can be referred to by us is the major of design science of The Hong Kong Polytechnic University, whose setting of curriculum is largely different from that of the mainland, without specific major boundary but covering a lot of aspects. Its curriculum almost covers all directions of design, such as test tailoring of clothes, methods for expression of fashion dress, visual transmission, electronic image introduction, material technology, industrial design, form art, design semantics, architectural construction, advertising etc. Such seemingly immethodical curriculums actually construct a systematic knowledge network; besides, such curriculum design is actually the cultivation of creativity and training of creative thinking.

\section{Popularization of studios}

Apart from the traditional teaching, the studio pattern is widely applied by the artistic design institutions of in Europe and America; it refers to a type of participatory, experiential and interactive learning pattern, which is an organization pattern with a small team of 10 to 20 members, who jointly discuss a topic through activities, discussions, short-time speeches and many other ways under the leadership of a host, who is experienced in a certain field and is the core of the team. Over recent years, many artistic colleges have been applying the studio pattern to teach their artistic design courses, such as the HPS Laboratory of Communication University of China. The studio-system teaching pattern, which has been fully developed in foreign design teachings, is aimed at letting students to train their abilities through solving specific problems so as to excellently solve actual problems. The capable colleges can either fully change their teaching patterns through building studios or develop practice teaching via exploring the pattern of researching subjects to increase the guiding and procedural courses. The studio-system teaching method originated from Bauhaus, the founder of which is Gropius, one of the founders of modern architectural design, who advocated "equal importance for art and skill"; students are apprentices and theoretical lecturers are their tutors, who teaches theoretical courses and lead their professional development; besides, the teachers who teach the courses of technical fabrication are "masters", mainly engaged in practice teaching. The studios can improve the students' abilities of solving problems, design creativity, investigation and 
research and can also enable the students to convert their theoretical abilities into their own actual skills.

\section{Conclusion}

In conclusion, to develop the creative industry is not to simply copy the traditional culture but lies in the talents' wisdom, inspiration and imagination; artistic design education is the key factor for the development of creative industry. Therefore, actively innovating the pattern of artistic design teaching and training the artistic talents with excellent creativity are of great importance to the cultural creative industry of our country.

\section{References}

[1] Fan Yugang. “Cultural Creativity” Drives the Future of China People's Tribune, 2011(13): 13-16

[2] Gong Qinyin. Reflection and Prospect: Artistic Design Education under the View of Creative Industry Art Education, 2009(28):24-27

[3] Liu Xiping: Strategies for Training the Talents of Cultural Creative Industry People's Tribune, 2010(13):55-58

[4] Chen Xuanrong. Exploration on Problems of Training of Talents Majoring in Design in Colleges and Universities Faced with the Creative Industry Education and Occupation, 2011(30): 123-145 